\title{
Disaster risk from a macroeconomic perspective: a metric for fiscal vulnerability evaluation
}

\author{
Omar D. Cardona, Mario G. Ordaz, Mabel C. Marulanda, Martha L. Carreño \\ and Alex H. Barbat ${ }^{1}$
}

The Disaster Deficit Index (DDI) measures macroeconomic and financial risk in a country according to possible catastrophic scenario events. Extreme disasters can generate financial deficit due to sudden and elevated need of resources to restore affected inventories. The DDI captures the relationship between the economic loss that a country could experience when a catastrophic event occurs and the availability of funds to address the situation. The proposed model utilises the procedures of the insurance industry in establishing probable losses, based on critical impacts during a given period of exposure; for economic resilience, the model allows one to calculate the country's financial ability to cope with a critical impact. There are limitations and costs associated with access to resources that one must consider as feasible values according to the country's macroeconomic and financial conditions. This paper presents the DDI model and the results of its application to 19 countries of the Americas and aims to guide governmental decision-making in disaster risk reduction.

Keywords: contingent liabilities, Disaster Deficit Index, economic resilience, fiscal sustainability, probable losses, seismic vulnerability

\section{Introduction}

Disaster risk is not only associated with the occurrence of intense physical processes, but also with the conditions of vulnerability that favour or facilitate disasters when these processes transpire. Disaster risk management requires the measuring of risk by taking into account not only the expected physical damage, the number of victims and equivalent economic loss, but also social, organisational and institutional factors (Carreño, Cardona and Barbat, 2007a, 2007b). Difficulty in achieving effective disaster risk management has been, in part, due to a lack of a comprehensive conceptual framework of disaster risk to facilitate a multidisciplinary evaluation and intervention. Most existing indices and evaluation techniques do not adequately express risk and are not based on a holistic approach that invites the intervention of vulnerability. It is necessary to make risk manifest itself in various ways, according to different decision-makers in diverse organisations and institutions. If risk is not presented and explained in a way that attracts the attention of stakeholders, it will not be possible to make progress in reducing the impacts. The various planning agencies dealing with the economy, environment, housing, infrastructure, agriculture or health, to mention but a few relevant areas, must be made aware of the risks 
that each sector faces. From another perspective, different levels of government should be considered, taking into account that risk is different at the local level (a community or a city) as compared to the national level. Risk is more detailed on a micro-social or micro-territorial scale. When results are aggregated at larger scales, the resolution is lower. Therefore, the information required, the risk intervention actions, the decision-making, the social actors and the stakeholders become different at each level. In this regard, appropriate evaluation tools are necessary to make it easy to understand risk problems and to guide the decision-making process. It is fundamentally important to understand how vulnerability is generated and how it increases. In addition, performance benchmarks are needed to facilitate access by decision-makers to relevant information as well as the identification and proposal of effective policies and actions.

Models to estimate the impact of disasters on economic growth have been developed, such as the model used in the Hot Spots project of the World Bank (2004) and the one by the United Nations Development Programme (UNDP, 2004) to estimate the Disaster Risk Index (DRI), which measures the relative vulnerability of countries to three key natural hazards - earthquakes, tropical cyclones and floods-
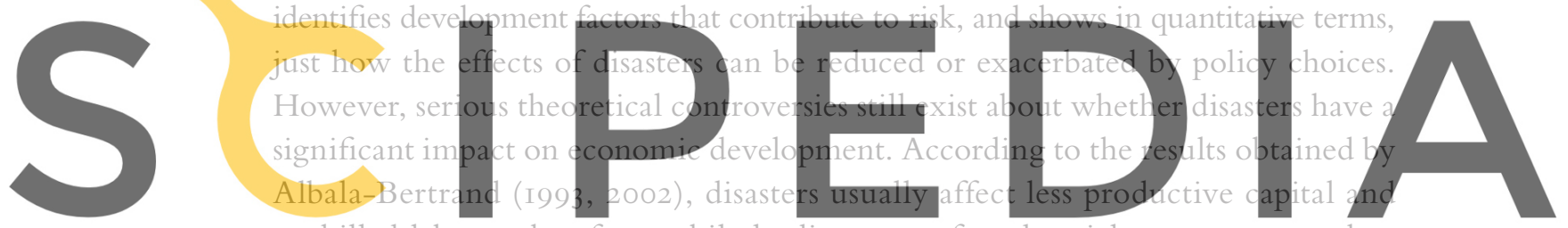

unskilled labour; therefore, while leading to profound social consequences, they

Register for free athttps prawh.seipedia.comfo downtoad the sersion without the watermark formulated by the International Institute for Applied Systems Analysis (IIASA) (Mechler et al., 2006) and by Freeman et al. (2002a, 2002b). Benson (2003) and the Economic

Commission for Latin American and the Caribbean (ECLAC, 2003), among others, argue that, in the long run, such impacts may be important for certain economies. The Institute of Environmental Studies (IDEA) (2005) of the National University of Colombia, in Manizales, presents an analytical approach to growth and disasters. It concludes that, 'in the stationary state', disasters may reduce the level of savings in society and thus the amount of capital and income per person, that is, recurrent and random disasters affect per capita income and growth rates in the long term.

\section{System of indicators}

The system of indicators was developed by IDEA for the Inter-American Development Bank, within the framework of its Program of Indicators for Disaster Risk and Risk Management in the Americas. Programme reports, technical details and the application results for the countries in the Americas can be consulted at http:// idea.unalmzl.edu.co (Cardona, 20ı0; Carreño, Cardona and Barbat, 2005; IDEA, 2005). 
The system of risk indicators was proposed to enable the depiction of disaster risk at the national level, permitting the identification of key issues by economic and social category. It also makes possible the creation of national risk management performance benchmarks in order to establish performance targets for improving management effectiveness. Four components or composite indicators were designed to represent the main elements of vulnerability and to show each country's progress in managing risk. The Disaster Deficit Index (DDI) measures country risk from a macroeconomic and financial standpoint when it faces possible catastrophic events. The Local Disaster Index (LDI) attempts to identify the social and environmental risk that derives from more recurrent lower level events, which are often chronic at the local and sub-national level. The Prevalent Vulnerability Index (PVI) characterises prevailing vulnerability conditions reffected in exposure in disaster-prone areas, socioeconomic fragility and a lack of social resilience in general. Lastly, the Risk Management Index (RMI) reflects the organisational, development and institutional action taken to reduce vulnerability and losses, to prepare for crisis and to recover efficiently.

The system covers different aspects of the risk problematic and takes into account aspects such as: potential damage and loss due to the probability of extreme events;
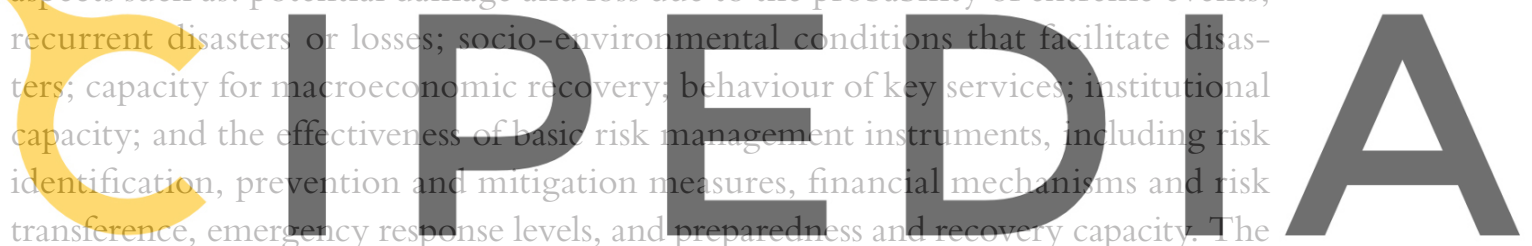

system was designed to permit measurement and monitoring over time and the

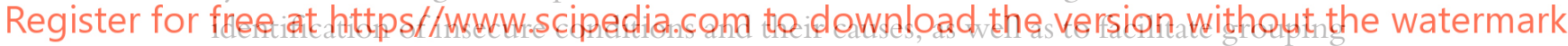

and comparison of countries using criteria related to hazard levels and the socioeconomic conditions that affect vulnerability levels.

The main objective of this paper is to present the DDI model and the potential macroeconomic and financial impacts on a country in the event of a catastrophe. Likewise, the results of an evaluation of I 4 countries of the Americas with regard to the dimensions of fiscal exposure and potential deficit in the countries are presented. Finally, the paper identifies and proposes possible effective governmental policies and actions through risk transfer mechanisms, using insurance and reinsurance, contingency credit or other instruments offered on the capital market.

\section{Disaster Deficit Index}

The DDI measures country risk from a macroeconomic and financial perspective according to possible catastrophic events. It captures the relationship between the economic loss that a particular country could bear when a catastrophic event takes place and the implications in terms of available external and internal resources to cope with the situation. To calculate the index, one must estimate the critical impacts 
during a given period of exposure, as well as a country's financial ability to deal with the situation. Construction of the DDI necessitates undertaking a forecast based on historical and scientific evidence, as well as measuring the value of infrastructure and other assets and services that are likely to be affected. The DDI represents the relationship between the demand for contingent resources to cover the losses, $L_{R}{ }^{P}$, caused by the Maximum Considered Event (MCE), ${ }^{2}$ and the public sector's economic resilience, $R_{E}{ }^{P}$, that is, the availability of internal and external funds to restore affected inventories. ${ }^{3}$ Thus, the DDI is calculated as follows:

$$
D D I=\frac{L_{R}{ }^{P}}{R_{E}{ }^{P}}
$$

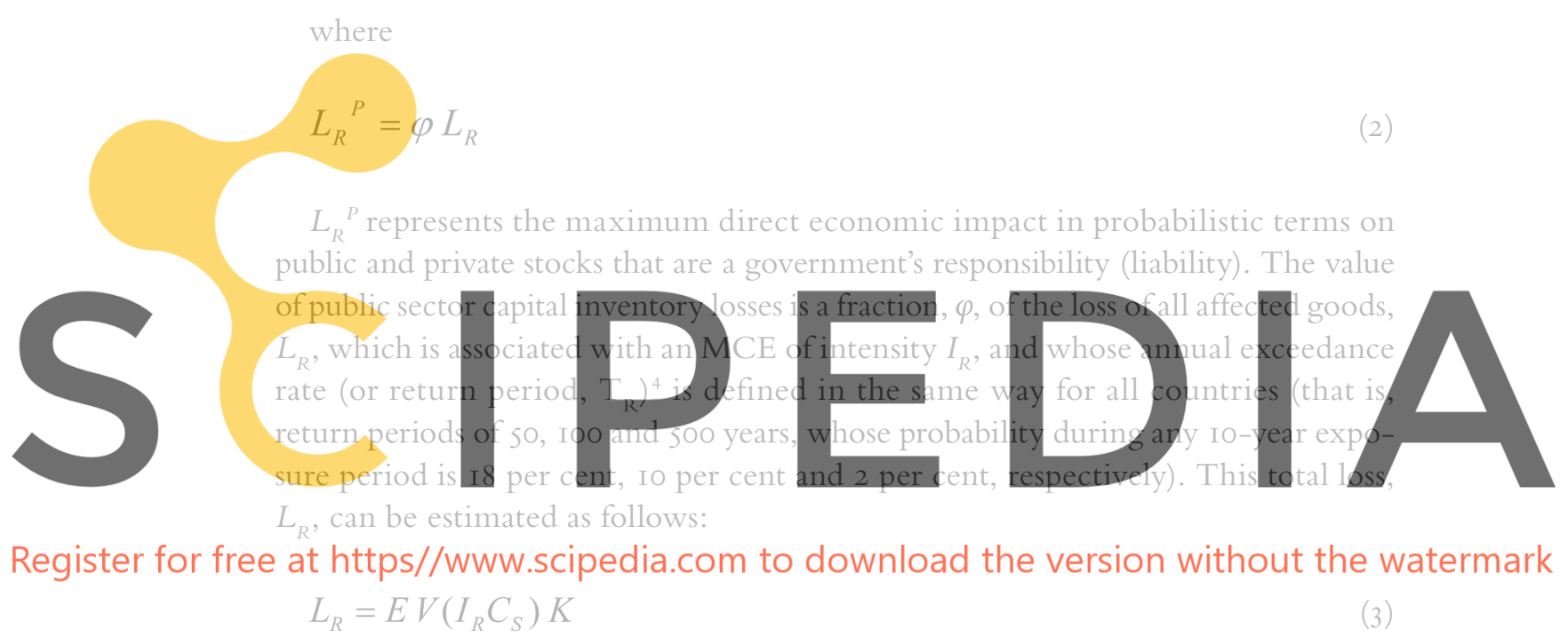

$E$ is the economic value of all property exposed; $V()$ is the vulnerability function, which relates the intensity of the event to the fraction of the value that is lost if an event of such intensity takes place; $I_{R}$ is the intensity associated with the selected return period; $C_{S}$ is a coefficient that considers local site effects; and $K$ is a factor that corrects for uncertainty in the vulnerability function.

Economic resilience, $R_{E}{ }^{P}$ (the denominator of the index), is defined as:

$$
R_{E}{ }^{P}=\sum_{i=1}^{n} F_{i}^{P}
$$

$F_{i}^{P}$ represents the internal and external resources that were potentially available to a government, as the promoter of recovery and as owner of affected goods, when the evaluation was undertaken. Limitations and costs are associated with access to these resources and these must be taken into account as feasible values according to the macroeconomic and financial conditions of the country. In this evaluation, the following aspects have been considered: the approximate insurance and reinsurance payments 
Figure 1 Calculation of the DDI

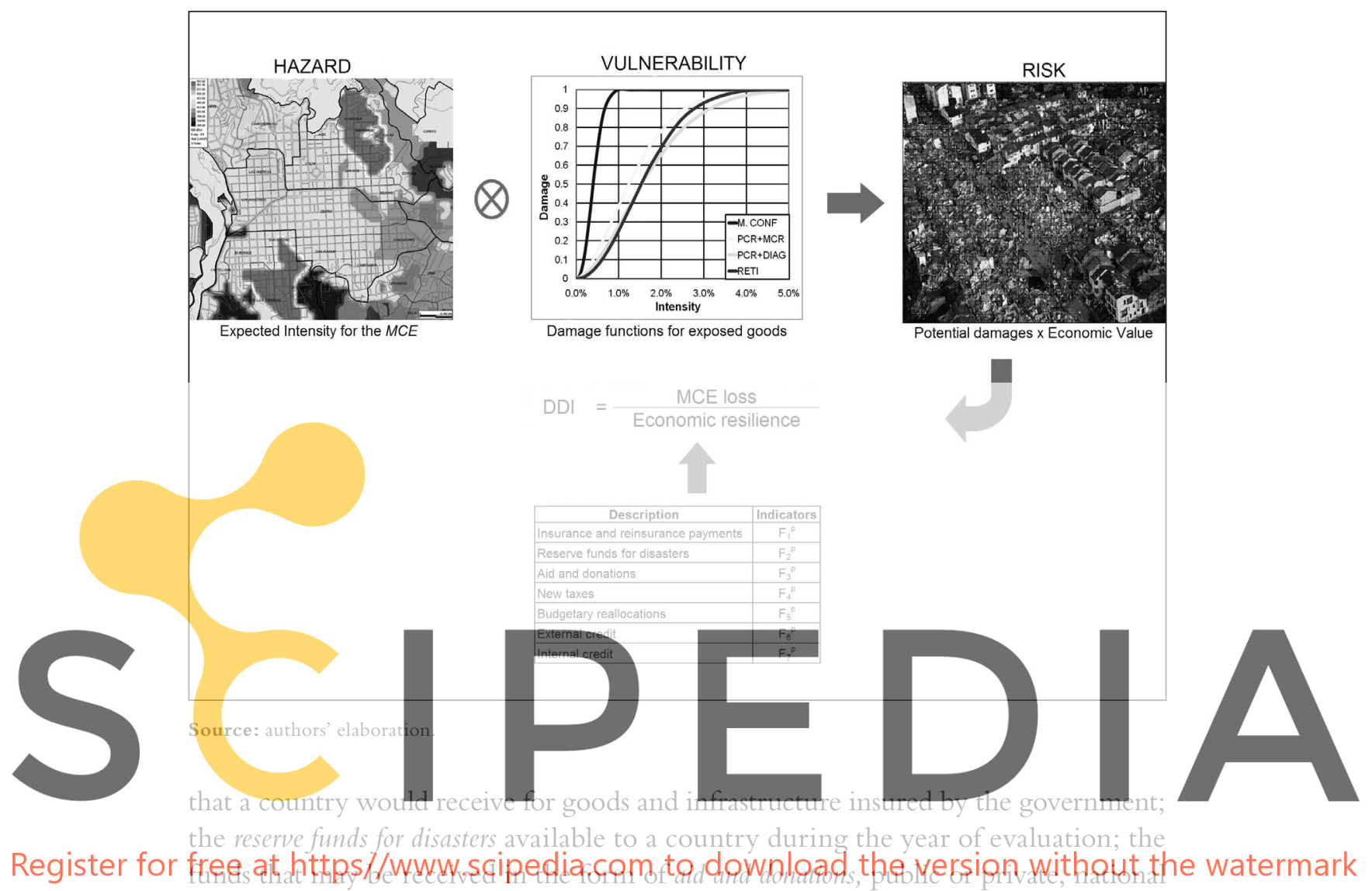

or international; the value of possible new taxes that a country could collect in the event of a disaster; the margin for budgetary reallocations in a country, usually corresponding to the level of discretional expenses available to the government; the feasible value of external credit that a country could obtain from multilateral entities and on the external capital market; and the internal credit a country could acquire from commercial sources and, at times, the Central Bank, when this is legal, signifying immediate liquidity. Figure I illustrates the way to calculate the DDI.

A DDI of greater than I.o reflects a country's inability to cope with extreme disasters even by going into as much debt as possible. The greater the DDI, the greater the gap between losses and a country's ability to respond to them. If constrictions on additional debt exist, this situation implies that it is impossible to recover.

To help put the DDI in context, we developed a complementary indicator, DDI', illustrating the portion of a country's annual capital expenditure, $E_{C}{ }^{P}$, that corresponds to the expected annual loss, $L_{y}{ }^{P}$, or the pure risk premium. ${ }^{5}$ That is, DDI' shows the percentage of the annual investment budget needed to pay for future disasters.

$$
D D I^{\prime}=\frac{L_{y}{ }^{P}}{E_{C}{ }^{P}}
$$


The pure premium value is equivalent to the approximate annual average investment that a country would need to cover losses associated with major future disasters. The DDI' can also be estimated by considering the amount of sustainable resources due to inter-temporal surplus, $S_{i}^{P}$. Henceforth, the percentage of the potential savings, at present value, that the technical premium would represent is:

$$
D D I^{\prime}=\frac{L_{y}{ }^{P}}{S_{I}{ }^{P}}
$$

The sustainable amount of resources due to inter-temporal surplus, $S_{i}^{P}$, is the saving, calculated over a IO-year period, that the government can access to cope best with disasters (IDEA, 2005). What one needs to know is whether the government, from a traditional standpoint, complies with its inter-temporal budgetary restriction. That is to say, if expenditure and income flows guarantee-in present-value terms - that current and future primary surpluses permit the cancelling of the current stock of debt. In other words, financial discipline requires that government action be limited and that financial capacity to deal with disasters complies with the inter-temporal restriction of public finances. In the event that annual losses exceed
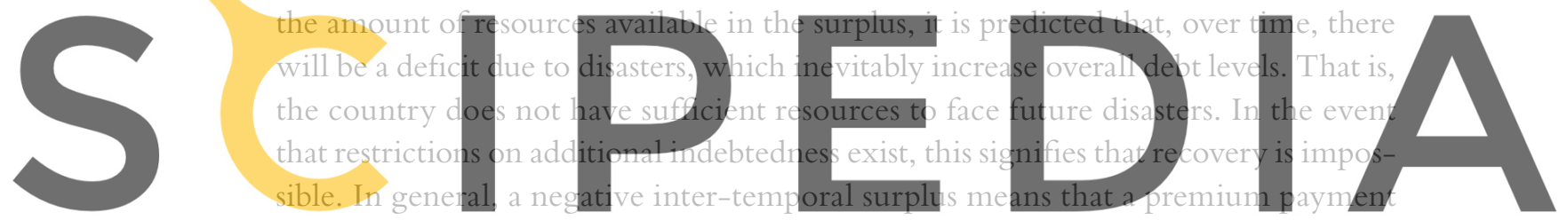

would increase the existent deficit.

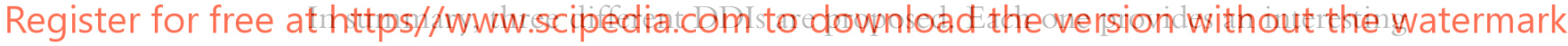
and useful figure, for a ministry of finance and economics, related to the potential financial sustainability problem of a country with regard to potential disasters. Yet, together, they paint a compressed picture of the fiscal vulnerability of a country due to disasters. Below we consider the theoretical framework of risk and the variables involved in equation 3 from a specific hazard and vulnerability perspective.

\section{Estimating probable losses}

Computation of losses in future natural hazard events (index numerator) is always a complex problem. Due to the uncertainties of this process, one must regard losses as random variables, which can only be known in a probabilistic sense, that is, through their probability distributions. Consequently, such an approach has been adopted in this model (Ordaz and Santa-Cruz, 2003). Given existing knowledge, it is clearly theoretically impossible to predict the occurrence and magnitude of all future natural hazard events. In view of the uncertain nature of the processes involved, a second-best choice is to estimate the probability distribution of occurrence of all future impacts. In general, however, this estimation is also an immense task. 
Figure 2 Example of a PML curve and the results for several return periods
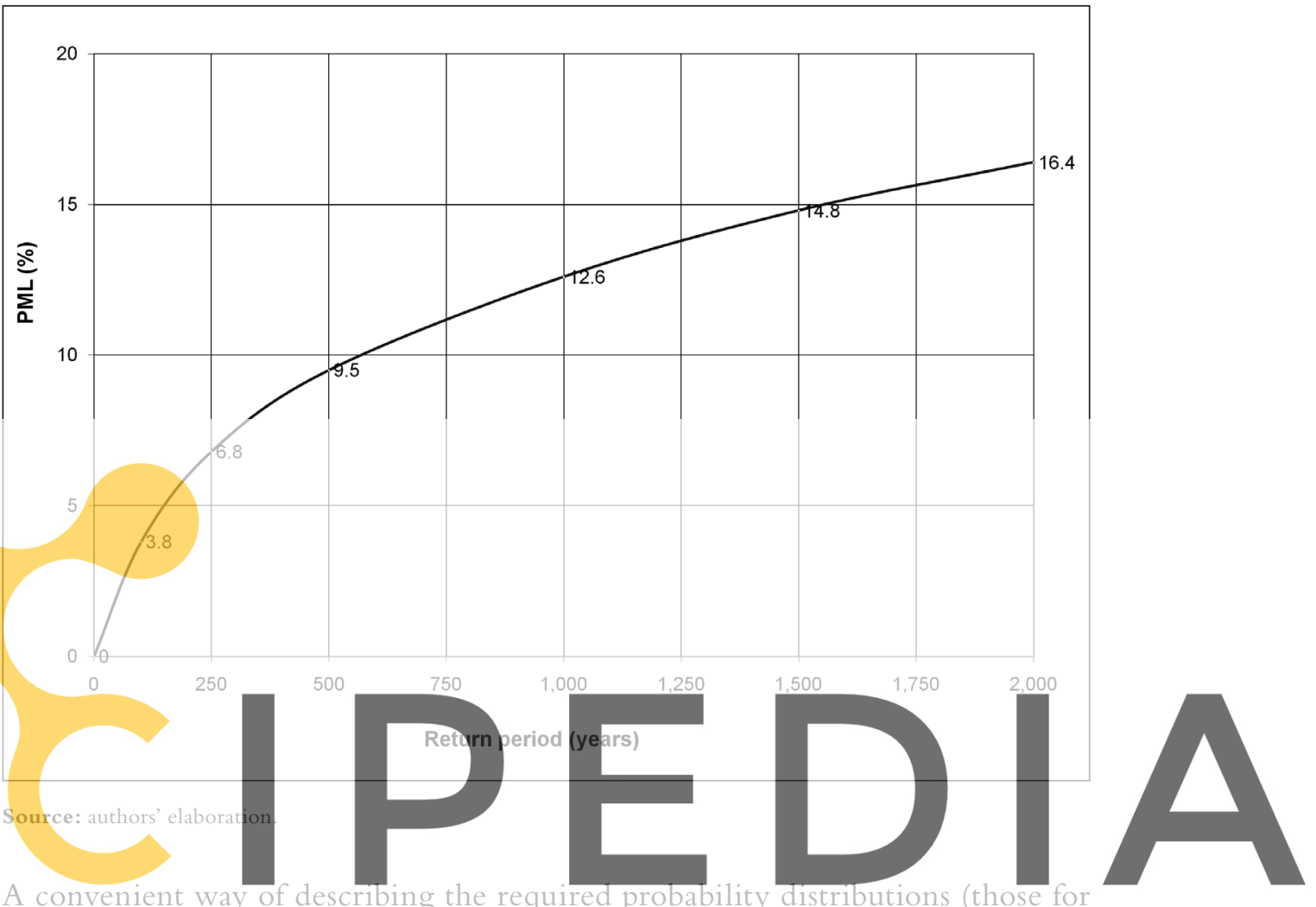

Register for free at https $/$ why scipediacom to download the version without the watermark of the physical losses (loss exceedence curve (LEC)). This curve indicates the fre-

quency of the events that would generate losses equal to or greater than a given

loss; the inverse of the exceedance rate is the return period. The probable maximum loss $(\mathrm{PML})^{7}$ curve is equivalent to the LEC. Figure 2 provides an example of this risk metric. ${ }^{8}$

\section{Hazard}

In this context, intensity is defined as a local measure of the disturbance produced by a natural event to those physical characteristics of the environment relevant to the case being study. For all types of hazards, it is almost impossible to describe the intensity using a single parameter. For instance, when dealing with earthquake hazards, the peak ground acceleration offers some general information on the size of the ground motion, but it does not give indications about frequency content. This is crucial for an accurate estimation of structural response. Hence, a single parameter description of intensity will always be incomplete. However, a multi-variable description of intensity is far too complex with regard to our goals (actually, very few, if any, risk assessments undertaken in the past have considered multi-variable descriptions of intensity). We propose to use a single measure of intensity for each type of hazard 
that correlates well with damage and for which hazard measures are relatively easy to obtain. One should note that, since we are mainly interested in disasters that have an economic impact at the national level, we have restricted ourselves to those hazards that produce large, immediate economic losses, such as earthquakes or hurricanes. While other hazards, such as landslides, are extremely important at the local level, and historically have claimed many victims, their economic impact has been limited. Slow on-set disasters, such as a drought, are also very important, but their economic effects are deferred over time. As these do not have immediate effects, they are beyond the scope of the proposed estimation model.

In many cases, hazard assessments are obtained from regional studies, or by assuming average environmental conditions. For example, seismic hazard maps are usually produced by assuming average, firm soil conditions, that is, no significant amplification of seismic intensity due to soft soil. Furthermore, wind velocity maps are generally produced assuming average exposure conditions, that is, velocities are not obtained for sites on hills, but for reference sites. For each type of hazard, though, particular environmental characteristics may exist in the cities under study that cause intensities to be greater or less than those in the neighbourhood. In other words, environmental characteristics may exist that differ from those corresponding to the
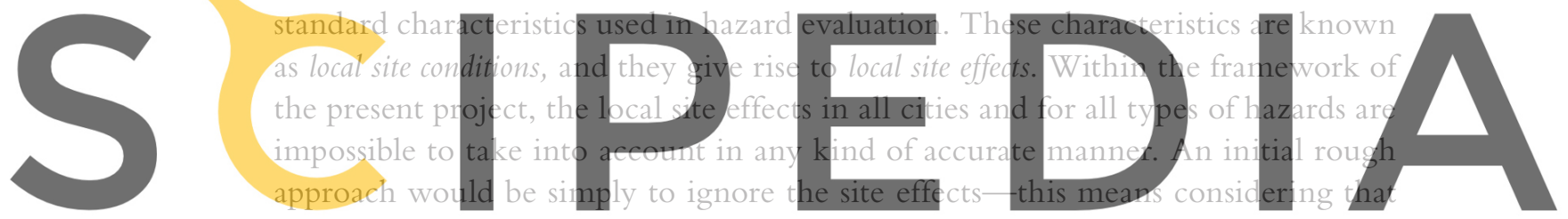

$C_{\mathrm{S}}=\mathrm{I}$ in equation 3. However, there are cases in which the local site effects cannot

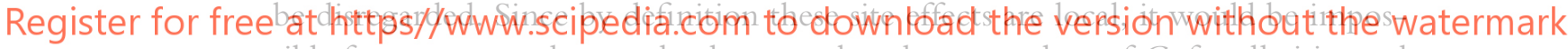
sible for us to accord general rules as to the adequate values of $C_{s}$ for all cities and types of hazard. In our view, the local experts who participate in loss estimation processes for different countries would have to assign appropriate values.

Once an appropriate intensity is selected for each type of hazard, a probabilistic description must be provided. Usually, the hazard is expressed in terms of the exceedance rates of intensity values. One must note that, for the purposes of this study, we require local information on a hazard, that is, exceedance rates of intensity at points or in cities of interest (one of our assumptions is that all property in a city is concentrated at a point or in a geographical area of limited size). In principle, a hazard curve must be constructed for every type of hazard and for every city under evaluation.

In the case of seismic hazard, the intensity is calculated by considering the sum of effects of all seismic sources in a certain influence area. The hazard, expressed in terms of the exceedance rates of the peak accelerations for firm soil, $a$, is calculated as follows (Esteva, I970):

$$
v(a)=\sum_{i=1}^{i=N} \int_{M_{0}}^{M_{u}}-\frac{\partial \lambda}{\partial M} \operatorname{Pr}\left(A>a \mid M, R_{i}\right) d M
$$


The sum includes all of the seismic sources, $N$, and $\operatorname{Pr}(A>a \mid M, R i)$ is the probability of the intensity exceeding a certain value, given the earthquake's magnitude, $M$, and the distance between the $i^{\text {th }}$ source and the site, $R_{i}$. The $\lambda(M)$ function represents the activity rates of the seismic sources. The integral is calculated from $M_{0}$ to $M_{u}$, indicating that the contribution of all the magnitudes is taken into account for each seismic source. It is important to note that equation 7 would be exact if the seismic sources were points, but in reality they are volumes; therefore, the hypocentres are located not only in the centres of the sources but also, with equal probability, in any point inside the corresponding volume. Supposing that the intensity variable has a lognormal distribution given the magnitude and distance, the probability $\operatorname{Pr}\left(A>a \mid M, R_{i}\right)$ is calculated in the following way:

$$
\operatorname{Pr}(A>a \mid M, R)=\Phi\left[\frac{1}{\sigma_{\ln a}} \ln \frac{\operatorname{MED}(A \mid M, R)}{a}\right]
$$

$\Phi(\cdot)$ is the standard normal distribution, $\operatorname{MED}(A \mid M, R i)$ is the median value of the intensity variable (from the corresponding attenuation law), and $\sigma_{\mathrm{Ln} \text { a }}$ is the standard deviation of the natural logarithm of a. Equations 7 and 8 include both the attenu-
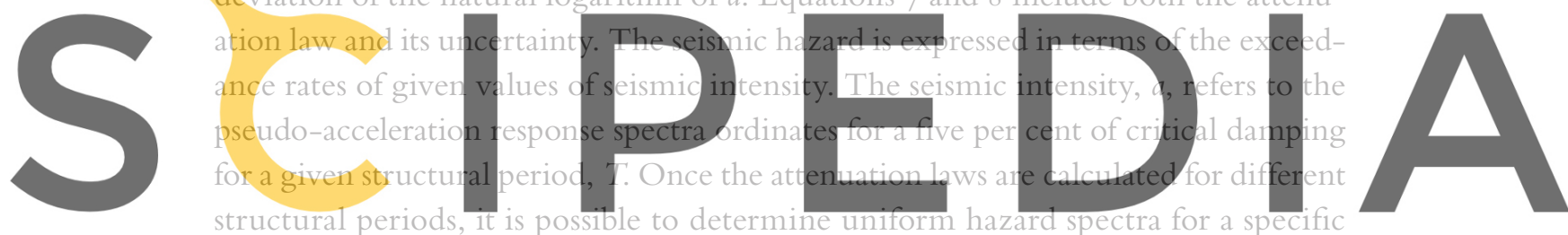

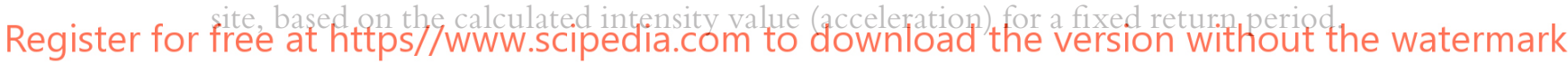

\section{Vulnerability}

As indicated in equation $3, V(I)$ is the vulnerability function, which relates the intensity of the event, $I$, to the expected fraction of the value that is lost if an event of such intensity takes place.

Vulnerability functions usually have shapes like those shown in Figure 3. A building is said to be more vulnerable than another one if more damage is expected to the former than the latter given similar hazard intensities. Vulnerability functions are highly hazard-specific. In other words, in the same city, buildings and infrastructure might be highly vulnerable to a certain hazard and much less vulnerable to another. As defined, vulnerability functions might change depending on technological, educational, cultural and social factors. For instance, for the same seismic intensity, buildings in a city might be more vulnerable than buildings in another city due to different construction technology or application of the seismic-resistant design. In a rigorous way, vulnerability functions should be expressed as follows:

$$
V(I)=V(I ; \phi)
$$


Figure 3 Representation of vulnerability functions

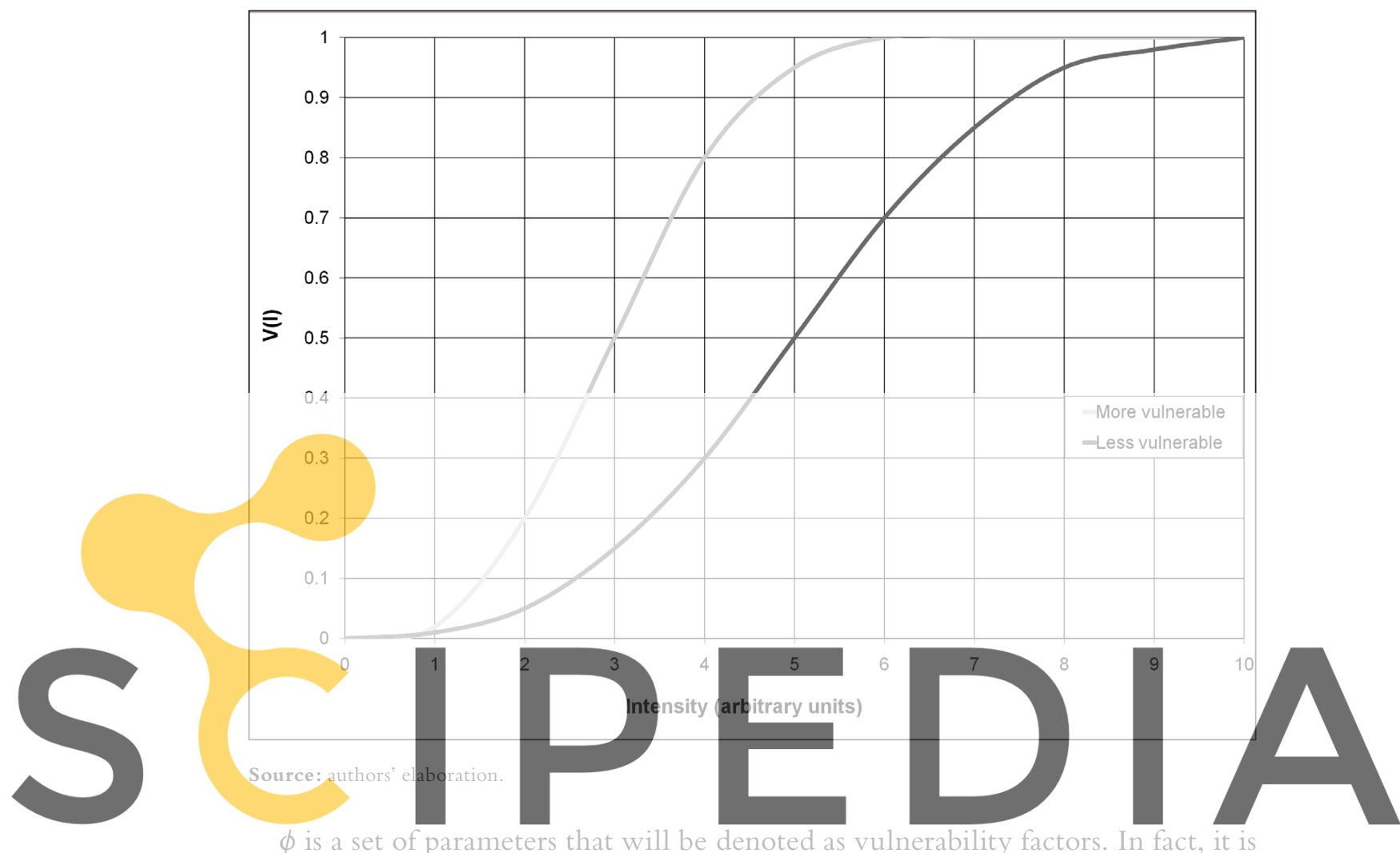

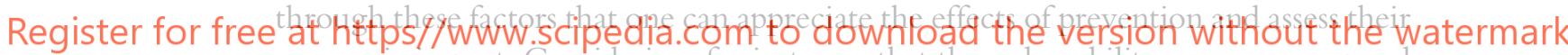
economic impact. Considering, for instance, that the vulnerability curves correspond to earthquake hazard, it is conceivable that the application of seismic-resistant design in a city (a change in one of the vulnerability factors) could move the vulnerability function from the 'more vulnerable' to the 'less vulnerable' case of Figure 2. Usually, investments in the development, implementation and enforcement of seismic regulations would be much lower than the amount saved by reducing vulnerability. Hence, improving design practices would be a sound decision even from an economic standpoint. Cardona et al. (2008) present a discussion of the probabilistic cost-benefit ratio.

From the above, one may deduce that we always see $V(I ; \phi f)$ as related to expected damage, that is, to the expected value (in a probabilistic sense) of the damage. Due to the uncertainties involved, it is impossible to predict damage resulting from an event with a given intensity. Thus, we try to predict its expected damage with $V(I ; \phi)$, keeping in mind that there are uncertainties that one cannot neglect. There are, of course, rigorous, probabilistic ways to account for this uncertainty. One way of solving this problem is to find a factor, which we call $K$ (see equation 3 ), that relates the loss estimator that would be obtained by accounting for the uncertainty with the loss estimators obtained by disregarding this uncertainty. Factor $K$ depends on three key variables: the uncertainty in the vulnerability relation; the shape of the intensity exceedance rate curve; and the return period. We found that, under reasonable 
Table 1 Parameters for some vulnerability functions

\begin{tabular}{|l|l|l|}
\hline Construction class & $\boldsymbol{a}$ & $\boldsymbol{\gamma}$ \\
\hline Non-reinforced masonry & 5.0 & 0.25 \\
\hline Confined masonry & 5.5 & 0.50 \\
\hline Reinforced concrete frames & 3.0 & 0.40 \\
\hline
\end{tabular}

hypotheses, a factor of $K=\mathrm{I} .2 \sim \mathrm{I} .3$ is reasonable for our goals. ${ }^{9}$ Vulnerability functions can be expressed analytically using:

$$
V(I)=1-\exp \left\{\ln 0.5\left(\frac{I}{\gamma}\right)^{\alpha}\right\}
$$

$\alpha$ and $\gamma$ are parameters that define the shape of the function. Table I presents some values of $\alpha$ and $\gamma$ for some building constructions (Ordaz and Santa-Cruz, 2003).

So far, our analysis has been restricted to estimate losses in cities or regions of limited geographical size. Key to the definition of 'limited geographical size' is our hypothesis that everything within the city is affected simultaneously by the event being studied. In reality, damage during disasters varies, sometimes widely, even within a city, so our hypothesis hardly, if ever, holds, but this assumption has to be made for the sake of simplicity. However, for extensive regions, comprising several cities, perhaps hundreds of kilometres apart, it would be extremely risky to assume that everything is affected simultaneously. Therefore, we have to derive ways to combine the computed loss estimators for each city in order to obtain a reasonable combined estimator for the whole country. We call these rules aggregation rules. IDEA (2005) presents details of the mathematical relations between the exceedance rates and other interesting and useful measures of risk; it also sets out rigorous probabilistic ways to account for the vulnerability uncertainty and the rules of aggregation of losses.

Economic losses in cities due to natural events were evaluated using a simplified method to estimate the inventory of exposed assets based on proxy values validated by institutions and local consultants in each country. Basically, a set of parameters was estimated using: the cost per square metre of different construction classes; the number of constructed square metres in each main city in relation to the number of inhabitants; the distribution of built areas (public or private buildings); and the inventory of assets that, in case of a disaster, would represent a responsibility of the government. A set of local validations and random samples was produced to confirm the accuracy of these proxies. This approximated method allows government officials and local consultants to use the model with relatively little effort and without need of very detailed cadastral data.

\section{Potentially available resources}

Economic resilience (the denominator of the DDI) represents internal and external resources available to or accessible by the government when the evaluation was done. 
However, limitations and costs are associated with access to these resources, which one must take into account. Seven constraints are explicitly taken into consideration in this study:

$F_{1}^{p}$ corresponds approximately to the insurance and reinsurance payments that a country would receive for goods and infrastructure insured by the government. Insurance is an incipient business in developing countries and an insurance culture does not really exist yet. The vast majority of insurance payments made after large-scale events have been to the private sector, particularly to large industries. In various countries, it is mandatory to insure public assets, but this legal requirement is not complied with thoroughly, especially in decentralised territorial entities and local governments. A simple way of estimating the value of insured physical wealth is to calculate insurance expenses as a proportion of gross domestic product (GDP). For example, according to an accepted proxy supported by Freeman et al. (2002b), if it is equivalent to two per cent of GDP, then insurance companies will cover two per cent of losses.

$F_{2}^{p}$ corresponds to the reserve funds for disasters that a country has available during the evaluation year. Some countries have established calamity or disaster funds (annual budget funds or multi-year budget funds). In various countries, principal and sectoral funds may be found in different institutions and ministries, such as public works and infrastructure, health and civil defence. In addition, decentralised funds exist at different territorial levels. This value must be estimated as the sum of the national available reserves plus the reserves existing in the potentially affected areas.

$F_{3}^{p}$ represents the funds that may be received as aid and donations, public or private, national or international. Usually external aid is given for emergency response and few resources are made available for rehabilitation and reconstruction (Cummins and Mahul, 2009). After a major event, help is generally received in the form of food, clothing, tents, and equipment, but little in the way of cash. Detailed information often is not available regarding aid received from governments, non-governmental organisations (NGOs) and humanitarian aid agencies. To estimate this, one must conduct an approximate and realistic analysis of such aid as a percentage of losses during previous events. There are difficulties in producing this kind of estimate because it depends on the size of the donations and on the geopolitical concerns of the donors (Freeman et al., 2002b).

$F_{4}^{p}$ corresponds to the possible value of new taxes that countries could collect in the event of disasters. Taxes have been imposed and applied to financial and banking operations in the past (ranging between $2 \%$ and $3 \%$ ). Such taxation, though, may lead to contention and the transfer of savings abroad. In general, severe doubt exists as to the suitability of imposing such taxes due to their unpopularity. This value should take into account political feasibility. In some cases, it may be viable to introduce a transitory tax as was done in some countries to finance reconstruction.

$F_{5}^{p}$ estimates the margin for budgetary reallocations in each country. In countries where limitations and constitutional controls on budgets exist, this value usually corresponds 
to the margin of discretional expenses available to the government. In some countries, it depends on the political decision of competent authorities. However, restrictions exist that impede larger reallocations due to the inevitable obligations of public spending on such variables as salaries, social expenses and debt servicing. Equally, there may be accumulated obligations related to previous budgets. Reallocation of non-executed loans from multilateral organisations may be considered here. If it is impossible to obtain a precise estimate of the margin for budgetary reallocation, a rough approximation is 60 per cent of the investment in capital goods, as a percentage of GDP.

$F_{6}^{p}$ corresponds to the feasible value of external credit that a country could obtain from multilateral entities and on the external capital market. Generally, loan conditions with respect to multilateral financial institutions are more favourable but they are restricted with regard to the level of sustainability of external debt and the relationship between debt servicing and exports. Interest rates, in general, depend on per capita income. Access to credit on the international capital market depends on internal and external financial risk calculations, determining risk premiums and commercial rates for debt titles. No matter what, access to credit signifies an increase in debt servicing obligations and a reduction in a country's capacity to absorb new debt. Therefore, the maximum value of external credit should be estimated via an analysis of the obligations and limitations facing the government.

$F_{7}^{p}$ represents the internal credit a country may obtain from commercial and, on occasion, the Central Bank, when this is legal, signifying immediate liquidity. In addition, after a major disaster, it is possible at times to obtain resources from international reserves, although this type of operation is generally complicated and may signify a risk to the balance of payments. Credit with commercial banks also entails limitations and costs and depends on the workings of local credit markets. In general, these will be scarce. In weak markets, a large amount of credit may affect internal consumption, local investment and interest rates. Additional available credit should be estimated by taking into account capacity to pay the loan and the capacity of national capital markets.

Potentially available resources were calculated by making some assumptions that were discussed with economic authorities in the same way in all countries. Furthermore, IDEA (2005) presents a method for estimating taxes on financial transactions and a model for calculating the external financial situation of a country and access to internal credit, taking into account the associated uncertainties.

It is important to note that the assessment of potentially available resources is proposed while considering restrictions or feasible values and without considering possible associated costs of access to some of these funds and opportunity costs that could be important. To obtain more accurate values, some countries calculated the DDI using detailed catastrophe models and macroeconomic techniques and by taking into account not only the national level but also sub-national units and different development sectors. 


\section{Results of application of the DDI in the Americas}

Different DDI were calculated for I9 countries of Latin America and the Caribbean in the period 1980-2008, in ranges of five years (Cardona, 20I0). Information was gathered in coordination with the institutions of countries that were willing to participate in the programme and that are member states of the Inter-American Development Bank (IDB).

In general, according to results obtained for the past two decades, most countries show a significant lack of capacity to deal with potential losses in the case of extreme events, even if they are associated with 50- and Ioo-year return periods. Even though the situation was more critical for most countries in the I980s and the early I990s (the DDI climbed to more than 6.0), the current situation is still worrying given the increase in potential losses and the low economic resilience demonstrated by the majority of the countries. In 2008, the most critical situations were in Honduras, Haiti, Barbados and Dominican Republic, with a DDI of more than 5.o. Belize and Nicaragua were close behind with a DDI of more than 4.0. The left side of Figure 4 shows the DDI in 2008 calculated for an MCE with a 500-year return period (two per cent probability of occurrence in Io years).

The right side of Figure 4 shows the maximum loss, $L$, to the government during the same period. Government responsibility was restricted to the sum of losses associated with public sector buildings and housing for the lowest income population.

Figure 4 DDI and PML in 500 years

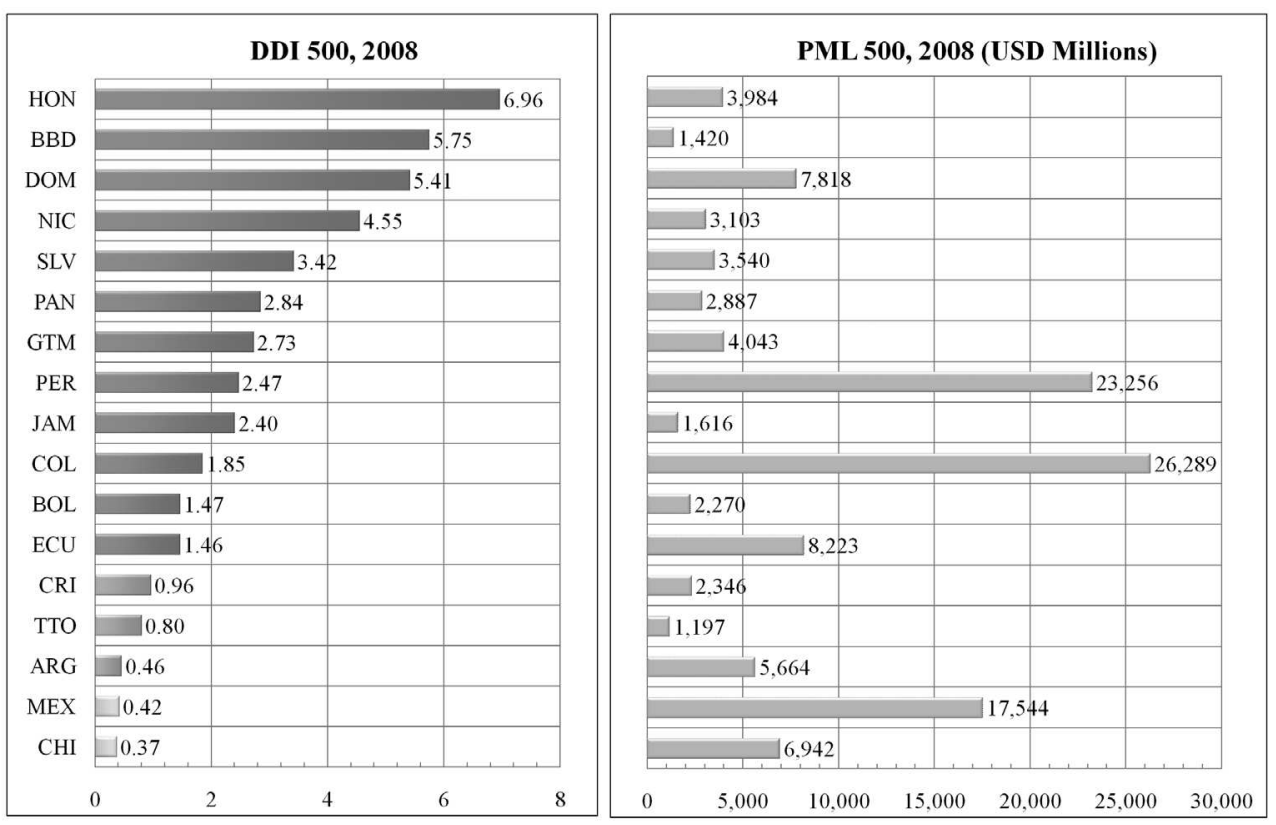

Note: $\mathrm{ARG}=$ Argentina, $\mathrm{BBD}=$ Barbados, $\mathrm{BOL}=$ Bolivia, $\mathrm{CHI}=$ Chile, $\mathrm{COL}=$ Colombia, $\mathrm{CRI}=$ Costa Rica, $\mathrm{DOM}=\mathrm{Dominican}$ Republic, ECU = Ecuador, GTM = Guatemala, HON = Honduras, JAM = Jamaica, MEX = Mexico, NIC = Nicaragua, PAN = Panama, $\mathrm{PER}=$ Peru, SLV $=$ El Salvador, TTO $=$ Trinidad and Tobago

Source: authors' elaboration. 
Figure $5 \mathrm{DDI}_{\mathrm{CE}}$ and Annual Probable Loss $(L y)$

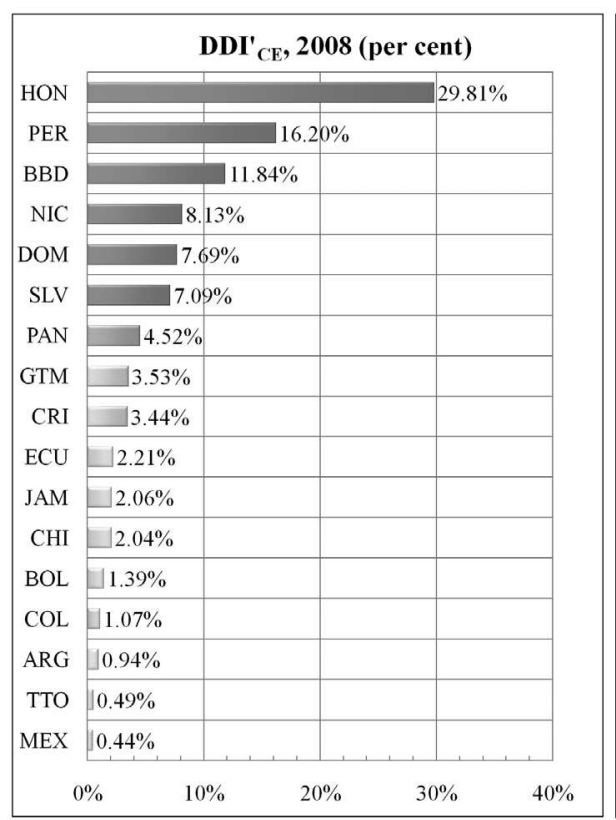

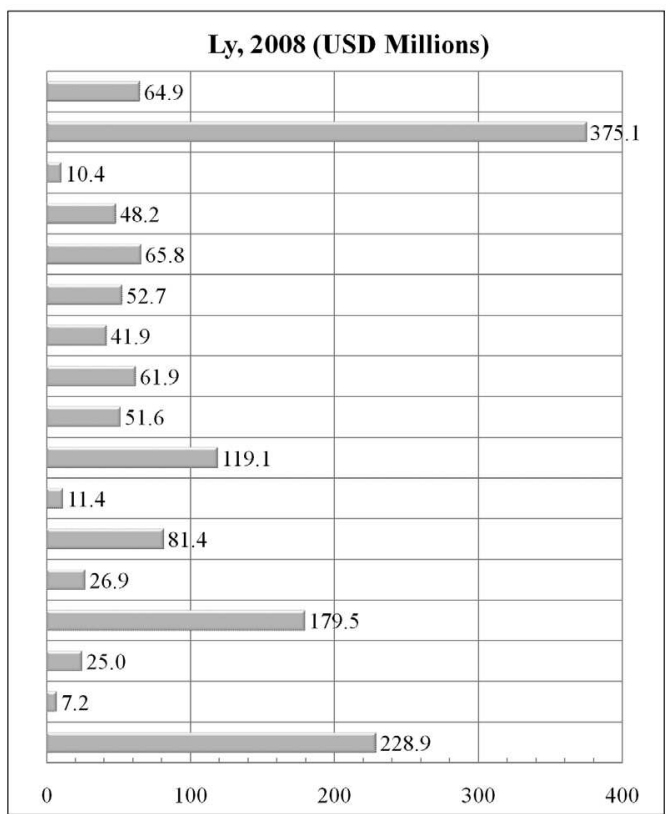

Note: $\mathrm{ARG}=$ Argentina, $\mathrm{BBD}=$ Barbados, $\mathrm{BOL}=$ Bolivia, $\mathrm{CHI}=$ Chile, $\mathrm{COL}=$ Colombia, $\mathrm{CRI}=$ Costa Rica, $\mathrm{DOM}=$ Dominican Republic, $\mathrm{ECU}=$ Ecuador, $\mathrm{GTM}=$ Guatemala, $\mathrm{HON}=$ Honduras, $\mathrm{JAM}=$ Jamaica, $\mathrm{MEX}=$ Mexico, $\mathrm{NIC}=$ Nicaragua, $\mathrm{PAN}=$ Panama, PER $=$ Peru, SLV $=$ El Salvador, TTO $=$ Trinidad and Tobago

Source: authors' elaboration.

Seventeen of the I9 evaluated countries have a DDI of more than I.o. Honduras, Haiti, Barbados and Dominican Republic with a DDI of 6.96, 6.29, 5.75 and 5.68, respectively, are in the most critical situation. Argentina and Mexico have a DDI of lower than I.o. This means that, although Mexico could face a gross loss of USD I7,544 million compared to USD 3,984 million for Honduras, it could access resources that would allow it to cover these losses. Honduras's low economic capacity to cope with extreme events explains this situation.

The left side of Figure 5 shows the DDI' ${ }_{\mathrm{CE}}$ for 2008 , while the right side shows the annual expected loss, $L y$. Honduras has the highest DDI' relative to capital expenditure - the annual cost of future disasters represents nearly 30 per cent of capital investment. Peru comes second with I6.2 per cent. Eleven countries have values below five per cent of the investment budget (capital expenditure of fixed assets).

The DDI is a risk proxy. Based on evaluations for the year 2008, Colombia, Mexico and Peru are prone to future extreme disaster risk. These countries are likely to suffer significant losses in the case of low probability, high consequence events. Ecuador and Chile also face relatively high loss; the Dominican Republic, Honduras and Guatemala are in the mid-range of countries. Belize, Haiti and Barbados have a relatively poor ability to obtain reconstruction assistance, while Mexico may suffer high losses but its economic resilience is high. Argentina, Colombia and Bolivia have minor relative risk profiles for extreme events, but this does not mean that risk 
Table 2 Possible funds available to the government in 2008 (USD million) ${ }^{10}$

\begin{tabular}{|c|c|c|c|c|c|c|c|c|c|c|c|c|c|c|}
\hline & $F_{1}{ }^{p}{ }_{50}$ & $F_{1}{ }^{p}{ }_{100}$ & $F_{1500}{ }^{p}$ & $F_{2}{ }^{p}$ & $F_{350}^{p}$ & $F_{3100}{ }^{p}$ & $\mathbf{F}_{3500}{ }^{p}$ & $F_{4}{ }^{p}$ & $F_{5}{ }^{p}$ & $F_{6}{ }^{p}$ & $F_{7}{ }^{p}$ & $\mathrm{RE}_{50}$ & $\mathrm{RE}_{100}$ & $\mathrm{RE}_{500}$ \\
\hline ARG & 0.2 & 0.7 & 10.2 & 227 & 22.3 & 59 & 574 & 6,023 & 1,593 & 1,979 & 1,979 & 11,823 & 11,860 & 12,384 \\
\hline BBD & 3.2 & 8.7 & 47.4 & 0 & 8.2 & 21 & 147 & 0 & 52 & 0 & 0 & 64 & 82 & 247 \\
\hline $\mathrm{BOL}$ & 1.8 & 3.2 & 17.5 & 0 & 14.9 & 28 & 168 & 51.8 & 1,164 & 73 & 73 & 1,380 & 1,394 & 1,549 \\
\hline $\mathrm{CHI}$ & 5.8 & 13.6 & 82.6 & 0 & 84.6 & 209 & 1,418 & 0 & 2,396 & 7,374 & 7,374 & 17,235 & 17,368 & 18,645 \\
\hline $\mathrm{COL}$ & 2.3 & 6.1 & 42.1 & 50.61 & 155.1 & 376 & 2,500 & 1,539 & 10,106 & 0 & 0 & 11,852 & 12,077 & 14,237 \\
\hline CRI & 12.8 & 26.9 & 42.5 & 5.68 & 51.3 & 110 & 336 & 0 & 900 & 581 & 581 & 2,131 & 2,203 & 2,445 \\
\hline DOM & 3.9 & 10.7 & 46.9 & 0 & 56.5 & 145 & 816 & 0 & 513.4 & 34 & 34 & 642 & 737 & 1,444 \\
\hline ECU & 17.7 & 43.3 & 102.8 & 0 & 146.8 & 336 & 1,387 & 0 & 3,241 & 451 & 451 & 4,308 & 4,522 & 5,633 \\
\hline GTM & 6.9 & 16.4 & 36.4 & 2.86 & 48.7 & 115 & 390 & 0 & 1,053 & 0 & 0 & 1,111 & 1,187 & 1,482 \\
\hline HTI & 0 & 0 & 0 & 0 & 30.3 & 84.1 & 349.1 & 0 & 104 & 0 & 0 & 134 & 188 & 453 \\
\hline HON & 9.3 & 21.9 & 45.4 & 0 & 52.0 & 121 & 396 & 0 & 130.6 & 0 & 0 & 192 & 274 & 572 \\
\hline JAM & 0 & 0 & 0 & 5.13 & 22.7 & 65 & 259 & 0 & 409.3 & 0 & 0 & 437 & 479 & 673 \\
\hline MEX & 15.6 & 36.8 & 124.6 & 0 & 770 & 2,006 & 4,910 & 0 & 30,937 & 3,039 & 3,039 & 37,800 & 39,057 & 42,049 \\
\hline NIC & 3.9 & 9.1 & 19.9 & 0.08 & 37.9 & 89 & 306 & 0 & 355.4 & 0 & 0 & 397 & 454 & 682 \\
\hline PAN & 2.2 & 5.6 & 12.4 & 0 & 46.9 & 113 & 448 & 0 & 556 & 0 & 0 & 605 & 674 & 1,015 \\
\hline PER & 12.7 & 42.7 & 62.8 & 10.07 & 326.2 & 1,083 & 3,549 & 377 & 1389 & 2,013 & 2,013 & 6,142 & 6,929 & 9,415 \\
\hline SLV & 15.2 & 40.6 & 82.8 & 4.36 & 48.8 & 128 & 501 & 0 & 447 & 0 & 0 & 515 & 619 & 1,035 \\
\hline TTO & 0 & 0 & 0 & 0 & 4.8 & 12 & 101 & 0 & 883 & 257 & 257 & 1,402 & 1,409 & 1,499 \\
\hline
\end{tabular}

Note: $\mathrm{ARG}=$ Argentina, $\mathrm{BBD}=$ Barbados, $\mathrm{BOL}=$ Bolivia, $\mathrm{CHI}=$ Chile, $\mathrm{COL}=$ Colombia, $\mathrm{CRI}=$ Costa Rica, $\mathrm{DOM}=\mathrm{Dominican} \mathrm{Republic}, \mathrm{ECU}=\mathrm{Ecuador}, \mathrm{GTM}=\mathrm{Guatemala}$ HON $=$ Honduras, HTI $=$ Haiti, JAM $=$ Jamaica, MEX $=$ Mexico, NIC $=$ Nicaragua, PAN $=$ Panama, PER $=$ Peru, SLV $=$ El Salvador, TTO $=$ Trinidad and Tobago. 
is low. Large-scale losses are expected in Colombia but its capacity to deal with losses is relatively good.

In general, looking at the different results of the research, obtained from I9802008 in five-year periods, the risk associated with extreme events has increased over time in all of the countries (Cardona, 20I0). The main reason for this is the growing inventory and rising vulnerability of non-engineered dwellings because of a lack of control and the generation of slums and scattered districts in the main cities.

These indicators provide a simple way of measuring a country's fiscal exposure and potential deficit (or contingency liabilities) in case of an extreme disaster. They allow national decision-makers to gauge the budgetary implications of such an event and highlight the importance of including this type of information in financial and budgetary processes. These results underline the need to identify and propose effective policies and actions, such as using insurance and reinsurance (transfer mechanisms) to protect government resources or establishing reserves based on adequate loss estimation criteria. Other such actions include contracting contingency credits and, in particular, investing in structural (retrofitting) and non-structural prevention and mitigation to reduce potential damage and losses as well as the potential economic impact of disasters. Table 2 presents as disaggregation of economic resilience (IDEA, 2005; Cardona, 20I0).

Application of this model indicates that the countries of Latin America and the Caribbean face significant risks that have yet to be fully recognised or taken into account by individuals, decision-makers and society as a whole. These indicators represent a first step towards measuring risk so that it can be accorded the priority it deserves in the development process. Once risk has been identified and measured, activities can be implemented to reduce it and control it.

\section{Conclusion}

The approach proposed here is fundamentally a probabilistic risk model similar to those used for loss transfer and retention purposes. Consequently, it is substantially different to that used by the United Nations Development Programme (UNDP, 2004) to estimate the Disaster Risk Index (DRI) and the one used in the Hot Spots project of the World Bank (2004). It is also significantly different to approaches applied in the majority of models proposed to estimate the impact of disasters on economic growth.

Application of these indicators and an evaluation of the inventories of public assets reveal that Colombia and Mexico have implemented efficient insurance strategies and other mechanisms of risk transfer and retention, such as CAT bonds and contingency credits. In addition, given that the losses of low-income householders in Colombia are the responsibility of the government, coverage of poor people has been promoted in Manizales through the design of a collective private home insurance scheme based on cross-subsidies. Furthermore, taking into account fiscal vulnerability and sustainability, ministries of finance in Colombia and Mexico have made 
extreme disasters a contingent liability in their general financial balance sheets. Moreover, substantial programmes for structural retrofitting of hospitals, schools and other infrastructure have been promoted in the main cities of these countries.

\section{Acknowledgment}

This work occurred thanks to the financial support of the Inter-American Development Bank within the framework of the Program of Indicators for Disaster Risk and Risk Management for the Americas (Operations ATN/JF-7907-RG and RG-Ti579/ATN/ MD-II238-RG). Financial assistance was also received from the Spanish Ministry of Education and Science and the project benefited from FEDER funds; projects: CGL2005-0454I-C03-02 and Project PSE II-2005 (PSS-380000-2005-I4) HABITAT2030, CONSOLIDER and SEDUREC, REF. CSD2006-00060.

\section{Correspondence}

Omar D. Cardona, Universidad Nacional de Colombia, Sede Manizales, IDEA, Cra.27 No.64-6o, Manizales, Colombia.E-mail: odcardonaa@unal.edu.co

Mario G. Ordaz, Instituto de Ingeniería, Universidad Nacional Autónoma de México (UNAM), Mexico DF. E-mail: mors@pumas.iingen.unam.mx

Mabel C. Marulanda, Universidad Politécnica de Cataluña, Campus Norte, C/Gran Capitán s/n Mod. Cı, 08034, Barcelona, Spain. E-mail:mmarulan@cimne.upc.edu Martha L. Carreño, Universidad Politécnica de Cataluña, Campus Norte, C/Gran Capitán s/n Mod. Ci, o8034, Barcelona, Spain. E-mail: liliana@cimne.upc.edu

Alex H. Barbat, Universidad Politécnica de Cataluña, Campus Norte, C/Gran Capitán s/n Mod. CI, o8034, Barcelona, Spain. E-mail: alex.barbat@upc.edu

\section{Endnotes}

I Omar D. Cardona is Professor at the Universidad Nacional de Colombia; Mario G. Ordaz is Professor at the Instituto de Ingeniería, Universidad Nacional Autónoma de México (UNAM), Mexico; Mabel C. Marulanda is Research Assistant at the Universidad Politécnica de Cataluña, Spain; Martha L. Carreño is Postdoctoral Researcher at the Universidad Politécnica de Cataluña; Spain; and Alex H. Barbat is Professor at the Universidad Politécnica de Cataluña, Spain.

2 This model follows the example set by the insurance industry in establishing a reference point (the Probable Maximum Loss, PML) for calculating potential losses (ASTM International, I999; Ordaz and Santa-Cruz, 2003).

3 Freeman et al. (2002b) have proposed a similar approach to estimate the resource gap. They state that being able to access sufficient funds for reconstruction quickly after a disaster is critical for a country's ability to recover with minimal long-term consequences.

4 Return period, $T_{r}$, is the inverse of the loss exceedance rate, representing the mean interval of time in which a given loss occurrence is expected. 
5 Pure risk premium is equal to the average annual loss divided by the replacement value of the asset, usually expressed as a rate per mille (\%o) of monetary value. Average annual loss is the expected loss per year. Computationally, it is the sum of products of event expected losses and event annual occurrence probabilities for all stochastic events considered in the loss model. In probabilistic terms, it is the mathematical expectation of the annual loss.

6 The Loss Exceedance Curve represents the annual frequency with which a loss of any specified monetary amount will be exceeded. This is the most important catastrophe risk metric for risk managers, since it estimates the amount of funds required to meet risk management objectives. The LEC can be calculated for the largest event in one year or for all (cumulative) events in one year. For risk management purposes, the latter estimate is preferred, since it includes the possibility of one or more severe events resulting from earthquakes.

7 Probable maximum loss represents the loss amount for a given annual exceedance frequency, or its inverse, the return period. The election of a return period depends on a stakeholder's risk tolerance; for example, in the insurance industry, the return periods used to define the PML vary between 200-year loss and I,500-year loss.

8 A large body of work exists on earthquake loss assessments. See, for example, the ATC-I3 (Applied Technology Council, I985) and the HAZUS (NIBS, I999), which are considered outstanding methods. See also Coburn and Spence (I992) and EERI (I997). Cardona et al. (2008) provide details of modular risk modelling.

9 Note that if a constant factor $\mathrm{K}=\mathrm{I} .2$ is used for all countries, cities and types of hazard then it becomes irrelevant for comparison purposes. However, we prefer to deal with $\mathrm{K}$ explicitly for two reasons. The first is of symbolic nature: it helps us to keep in mind that our assessment process is uncertain and that we must account for uncertainty in a formal way. The second reason is that, as defined, our loss estimators have a clear meaning: they are economic losses, measured in monetary units. Thus, their scale is relevant.

Io Values equal to zero mean that it is impossible to access resources due to economic restrictions.

\section{References}

Albala-Bertrand, J.M. (I993) 'Natural disaster situations and growth: a macroeconomic model for sudden disasters impacts'. World Development. 2I(9). pp. I4I7-I 434.

Albala-Bertrand, J.M (2002) 'Urban disasters and globalization'. In A. Kreimer, M. Arnold and A. Carlin (eds.) The Future of Disaster Risk: Building Safer Cities. Disaster Risk Management Series No. 3. World Bank, Washington, DC. pp. 75-82. http://www.unisdr.org/eng/library/Literature/ 7759.pdf (accessed on 7 May 20IO)

ASTM International (I999) Standard Guide for the Estimation of Building Damageability in Earthquakes. E 2026-99. ASTM International, West Conshohocken, PA.

ATC (Applied Technology Council) (1985) Earthquake Damage Evaluation Data for California. ATC-I3 (FEMA). ATC, Redwood City, CA.

Benson, C. (2003) The Economy-wide Impact of Natural Disasters in Developing Countries. University of London, London.

Cardona, O.D. (2010) Indicators of Disaster Risk and Risk Management: Program for Latin America and the Caribbean. Summary Report (online). Inter-American Development Bank (IDB)/Institute of Environmental Studies (IDEA) and ERN-AL, Manizales. http://www.manizales.unal.edu.co/ ProyectosEspeciales/bid2/documentos/SummaryIndicatorsIDB-IDEA-ERN_Hti.pdf (accessed on I3 June 20I0).

Cardona, O.D., M.G. Ordaz, L.E. Yamin, M.C. Marulanda and A.H. Barbat (2008) 'Earthquake loss assessment for integrated disaster risk management'. Journal of Earthquake Engineering. I2(S2). pp. $48-59$. 
Carreño, M.L, O.D. Cardona and A.H. Barbat (2005) Sistema de indicadores para la evaluación de riesgos. CIMNE monograph IS-52. International Center for Numerical Methods in Engineering, Barcelona.

Carreño, M.L, O.D. Cardona and A.H. Barbat (2007a) 'A disaster risk management performance index'. Journal of Natural Hazards. 4I(I). pp. I-2O.

Carreño, M.L, O.D. Cardona and A.H. Barbat (2007b) 'Urban seismic risk evaluation: a holistic approach'. Journal of Natural Hazards. 4O(I). pp. I37-I72.

Coburn, A. and R. Spence (I992) Earthquake Protection. John Wiley \& Sons, Chichester.

Cummins, J.D. and O. Mahul (2009) Catastrophe Risk Financing in Developing Countries: Principles for Public Intervention. World Bank, Washington, DC.

ECLAC (Economic Commission for Latin American and the Caribbean) (2003) Manual para la estimación de los efectos socio-económicos y ambientales de los desastres. ECLAC and the World Bank, Washington, DC.

EERI (Earthquake Engineering Research Institute) (I997) 'Theme issue: loss estimation'. Earthquake Spectra. I3 (4).

Esteva, L. (1970) Regionalización sísmica de México para fines de ingeniería. Serie Azul 246. Engineering Institute, Universidad Nacional Autónoma de México (UNAM), Mexico.

Freeman, P.K., L.A. Martin, R. Mechler and K. Warner (2002a) Catastrophes and Development: Integrating Natural Catastrophes into Development Planning. Disaster Risk Management Working Paper Series. No. 4. World Bank, Washington, DC.

Freeman, P.K. et al. (2002b) Disaster Risk Management: National Systems for the Comprehensive Management of Disaster Financial Strategies for Natural Disaster Reconstruction. Inter-American Development Bank, Washington, DC.

IDEA (Institute of Environmental Studies) (2005) System of Indicators for Disaster Risk Management: Program for Latin American and the Caribbean. Main technical report (online). IDB/IDEA Program of Indicators for Disaster Risk Management, National University of Colombia, Manizales.

http://www.manizales.unal.edu.co/ProyectosEspeciales/bid2/documentos/SummaryreportIDB Updated2007Vi.pdf (accessed on I9 May 2010).

Mechler, R., S. Hochrainer, J. Linnerooth-Bayer and G. Pflug (2006) 'Public sector financial vulnerability to disasters: the IIASA CATSIM model'. In J. Birkmann (ed.) Measuring Vulnerability to Hazards of Natural Origin: Towards Disaster Resilient Societies. United Nations University Press, Tokyo. pp. $380-398$.

NIBS (National Institute of Building Sciences) (1999) Earthquake Loss Estimation Methodology HAZUS, Technical Manual, Vol. 1. Prepared by the National Institute of Building Sciences for the Federal Emergency Management Agency, Washington, DC.

Ordaz, M. and S. Santa-Cruz (2003) Computation of Physical Damage to Property due to Natural Hazard Events. IDB/IDEA Program of Indicators for Risk Management, National University of Colombia, Manizales. http://www.manizales.unal.edu.co/ProyectosEspeciales/bid2/documentos/MarioOrdaz_ SSantaCruzEMBarcelonaNov2003[I].pdf (accessed on I9 May 20Io).

UNDP (United Nations Development Programme) (2004) 'International patterns of risk'. Reducing Disaster Risk: A Challenge for Development. UNDP, Geneva. pp. 29-55. http://www.undp.org/cpr/ whats_new/rdr_english.pdf (accessed on 7 May 20Io).

World Bank (2004) Natural Disaster Hotspots: A Global Risk Analysis-Synthesis Report. Center for Hazards and Risk Research, University of Columbia, Palisades, NY. http://sedac.ciesin.columbia. edu/hazards/hotspots/synthesisreport.pdf (accessed on I9 May 2010). 